\title{
THE CONSISTENCY OF PERFORMANCE MANAGEMENT SYSTEM BASED ON ATTRIBUTES OF THE PERFORMANCE INDICATOR: AN EMPIRICAL STUDY
}

\author{
DOI: 10.12776/QIP.V18I1.314
}

JÁN ZÁVADSKÝ, VLADIMÍR HIADLOVSKÝ

Received 19 April 2014, Revised 7 June 2014, Accepted 10 June 2014

\section{INTRODUCTION}

Performance management system (PMS) and its consistency are mainly described in the work of Ferreira and Otley (2009) and Flapper, Fortuin and Stook (1996). However, we are not looking for the definition of PMS in our article but we want to set the premises of consistent PMS from the systems theory point of view. This assumption is based on homogenous group of attributes of the performance indicator (PI). In the article we want to answer to two basic questions:

(1) What are the attributes of the PI?

(2) What is the minimum set of attributes of the PI that we could say is consistent to the PMS?

We looked for answers to these questions through the empiric research realized in Slovak companies certified to the ISO 9001 standard. There is an assumption based on the system approach to management, including a PMS. The main objective of the research was to define the set of attributes of a PI and to find out which of these attributes are determined in the sample companies. Exploring the frequency of each attribute is the first step of our research. Next, we find the importance of each attributes determined by sampled companies. Last step of the research deals with the finding of a minimum number of PIs attributes that make a PMS functional and consistent. The consistency of a PMS is based not on maximum or minimum number of attributes, but on the same type of attributes for each PI used in a PMS on both the operational and strategic level. 


\section{LITERATURE REVIEW}

Flapper, Fortuin and Stook (1996) present a systematic method for designing a consistent performance management system to be used in practice where explicit attention is paid to the relations between the PIs. With a consistent performance management system (PMS) they intended a system that covers all aspects of performance that are relevant for the existence of an organization as a whole. Such a system should offer management quick insight into how well the organization is performing its tasks and to what extent the organizational objectives are being obtained. The method consists of three main steps: (1) defining performance indicators, (2) defining relations between performance indicators, and (3) setting target values or ranges of values for performance indicators. Ferreira and Otley (2009) are describing the structure and operation of performance management systems (PMSs) in a more holistic manner. Berry, et al. (2009) made a wider literature review in management control.

Performance management system can be defined in many different ways. Závadský and Závadská (2014) describe it as a part of business process models. It could be also defined as a management control system (Bisbe and Otley, 2004; Chenhall, 2003; Chenhall and Euske, 2007; Otley, 1994). Another point of view on PMS is a strategic view, in literature mostly described by Kaplan and Norton (1996), Kaplan and Norton (2000), Kaplan and Norton (2004) and Gavurová, Šoltés and Balloni, A. J. (2014). A critical view to their publications was presented by Otley (2008). Chenhall (2005) also refers to the Integrative strategic performance measurement system. In literature we are confronted with three important terms: (1) management control system, (2) performance measurement system (PMeS) and (3) performance management system. From our point of view the type of that system is not important because we can find the performance indicator in each one. Performance indicator is a subject of our research, especially its attributes that need to be defined.

Another view to PMS is the excellence models that include requirements for measurement and evaluation of the performance efficiency. There exists a number of these models. Evans, Ford, Masterson and Hertz (2012) explore how to further improve and achieve higher levels of performance in accordance to the Malcolm Baldridge Award. Abdullah, et al. (2012) present a conceptual framework for the development of a value-based total performance excellence model (VBTPEM) in organisations. This model signifies core values as a strategic component for an organisation to achieve total performance excellence and this extension integrates the intangible parts of performance measurement that have become a pivotal issue in many organisations.

An interesting work is presented by Doeleman, Have and Ahaus (2012). Their study deals with the moderating role of leadership in the relationship between management control as part of total quality management (TQM) and business excellence in terms of purposive change. Their results also indicate that transformational leadership is the most influential factor in the relationship 
between the management control construct and purposive change. It is concluded that organisations are strengthened by a management control system which is applied in combination with an intensive management communication approach in a context of transformational leadership.

Wang (2012) presents the results of a literature review which indicate the lack of an appropriate framework for evaluating organisational performance (OP) during crisis. He identifies key OP indicators and then he develops a multi-dimensional framework for evaluating OP during crises. Alfaro-Saiz, et al. (2011) describe how to use the information coming from applying the EFQM excellence model to analyse the perception that the members of an organisation have of it regarding their business vision. Heras-Saizarbitoria, Marimon and Casadesús (2012) present an empirical study of the relationships between the categories of the EFQM model.

There are several views on performance. We remind that the starting point of our research is neither view on a PMS. We are dealing with the homogeneity of any of these performance systems which basic element is the PI.

\section{DEFINING THE ATTRIBUTES OF THE PI}

At the beginning, we used an affinity diagram that helped us to clarify and to group various attributes of performance indicators. Affinity diagram are sometimes called diagram of relatedness or cluster chart is a suitable tool for creating and organizing information related to selected problem. Affinity diagram helps to sort this information into natural groups and to clarify the structure of solved problems. The diagram was created by teamwork and we used intuitive thinking. The professional composition corresponded with the issues that are being dealt with. The first step consists of a problem definition: what are the attributes of the PI? To make the team focus their attention, we wrote down the solved problem in a visible place. The task of the team was in the use of brainstorming to collect the attributes that could help solve the problem. The effort was to gain as many ideas as possible because there is an assumption that the more ideas are found the higher probability of their helpfulness in problem solving exists. We were writing down all gained ideas to the cards. The report was created by the coordinator of the brainstorming session and every attribute was clearly formulated. After the discussion the cards along with their gained ideas were lay out in a large space. Then the ideas were divided into natural groups by their relatedness. This activity was realized by each member of the team individually. The stage of grouping was finished by the coordinator. The important step was to name the related ideas that could help to characterize each group. At the end we created four groups of attributes of the PI: (1) formal attributes of the PI, (2) attributes of the PI's target value, (3) informational attributes of the PI and (4) attributes of the PI's evaluation. Each group consists of various attributes. Each set of attributes consists of 21 attributes of PIs. In Figure 1 are shown the groups and the attributes of the PI. 


\section{F: Formal attributes of the PI \\ F1: Name of the PI \\ F2: Relation to the business process (name and identification number of the process) \\ F3: Relation to the strategic goal \\ F4: Strategic goal (name and identification number of the strategic goal) \\ F5: Responsibility for the PI definition}

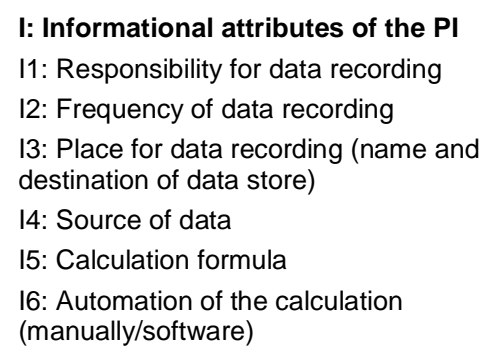

\section{T: Attributes of PI's target value}

T1: Responsibility for the target value definition T2: Unit of the PI

T3: Period defined for the target value achievement

T4: Determinants of the target value definition

T5: Target value (number)

\section{E: Attributes of the Pl's evaluation}

E1: Responsibility for the Pl's evaluation

E2: Frequency of the PI's evaluation

E3: Visualisation of the achieved performance

E4: Action in case of a performance gap

E5: Warning signals for the evaluator

Figure 1 - The four groups of the PI's attributes

\section{F: Formal attributes of the PI}

\section{F1: Name of the PI}

Each indicator should have a specific name which implies an area of the performance that is measured by this indicator. To make the indicator able to describe the context it is good to answer to the following question: How could we find out if the performance or strategic goal has been reached?

F2: Relation to the business process (name and identification number of the process)

This formal attribute refers to the connection of indicator to the specific business process.

\section{F3: Relation to the strategic goal}

There is a possibility that an indicator is related to operational or strategic level in a PMS. If the indicator is used for the measurement of strategic goals it refers to measurement and evaluation of strategic performance. The fact if the indicator belongs to first (strategic) or second (operational) level depends also on the utilization of the Balanced scorecard system. If this system was implemented in a company, it is obvious which indicators are part of the strategic set and which are part of the operational level of performance and what are the connections between them. If this approach is not used by company it is good to create a primary connection between strategic goals and indicators.

\section{F4: Strategic goal (name and identification number of the strategic goal)}

If there is a connection to strategic goal it is also necessary to name the strategic goal that is measured by the given PI. 


\section{F5: Responsibility for the PI definition}

If it is an operational level of performance and the indicator do not measure the strategic goal, the indicator can be defined by the process owner or by the line managers. If the indicator monitors the achievement of strategic goals, it is very important to follow specific principles of its definition. It means that the responsibility for the indicator definition usually lies with the top managers.

\section{T: Attributes of the PI's target value}

\section{T1: Responsibility for the target value definition}

It is very important to define the responsibility for the indicator definition but on the other hand from this definition it should be obvious where the responsibility for its target values definition lie. The target value is critical from the performance evaluation point of view and that is why its specification should be addressed to a specific employee.

T2: Unit of the PI

After creating a suitable indicator and defining the target value, the indicator should be clearly quantified in exact measurement units.

T3: The Period defined for the target value achievement

This characteristic determines the period on which the goal is set.

\section{T4: The Determinants of the target value definition}

Each target value should be based on real expectations and the existence of the assumption of its determination. It usually comes from retrospective analyses and future state forecasting. There exists a row of analytical, comparative and planning methods of determining the target value.

T5: Target value (number)

One of the indicator attributes is a goal and without target value the existence and monitoring of performance would hardly be realized.

\section{I: Informational attributes of the PI}

\section{I1: Responsibility for data recording}

The next responsibility is a determination for the employee who records the data necessary for measurement and evaluation of the performance. It is the third responsibility as an attribute of the performance indicator.

\section{I2: Frequency of data recording}

The next informational attribute that deals with the creation and distribution of information in connection to the business performance is a frequency of data recording. A dependable employee should clearly identify his responsibilities and frequencies of data recording to make the performance measurement realistic. If the collecting of data is automated, the frequency of data recording is defined by software.

I3: Place for data recording (name and destination of data store) 


\section{I4: Source of data}

If there is no definite value assignment of an indicator, it is important to determine the input data from which the final values are achieved. It is characteristic especially to synthetic indicators and relative indicators. If the calculation is necessary, it should always be clear what the partial sub indicators that are used for final value calculation are.

\section{I5: Calculation formula}

If the value of the PI is gained from various input values, the mechanism of final values calculation should be defined (if the calculation is not automated). In case of complex PI it is good to use automated calculation, because the evaluation of achieved performance is easier.

I6: Automation of the calculation (manually/software)

In this case it is important to determine which parts are necessary to be automated and which parts need to be calculated manually.

\section{E: Attributes of PI's evaluation}

E1: Responsibility for the PI's evaluation

Responsibility for the evaluation is usually connected with the responsibility for defining the target values. It means that one of the managers is managing "his" indicators.

\section{E2: Frequency of PI`s evaluation}

Employee who is responsible for the performance evaluation should know the frequency in which the performance of the selected process is evaluated by each indicator. If PMS is automated, it can automatically warn a responsible employee to evaluation need, or system is reporting a deviation.

\section{E3: Visualization of the achieved performance}

An important attribute of the PI that should be determined is a visualization of the performance results. It represents the selection of the method or the way of visualization of the results to the evaluator.

\section{E4: Action in case of the performance gap}

Situations that caused an insufficient performance can have specific causes with specific ways of solving them. For each PI there should be a defined procedure in the case that the performance is in either the "exceed" or "failure" interval.

\section{E5: Warning signal for evaluator}

The warning signal represents an alert to the person who is evaluating the achieved level of performance.

\section{EXPLORING THE PMS CONSISTENCY BY AN EMPIRICAL STUDY}

We performed an empirical study in Slovak companies certified to the ISO 9001. The sample selection was based on the assumption that certified enterprises use a 
system approach coming from the ISO 9001. A system approach should ensure the consistency of the whole quality management system. A system approach is a way of thinking, acting and solving problems from the complex point of view, in their internal and external context.

\subsection{Data collection}

The data for this empirical study was gathered using a structured questionnaire in the period from $2^{\text {th }}$ January 2013 to $30^{\text {th }}$ March 2013. According to the Slovak Statistical Office, at the time of our research $16.4 \%$ of all Slovak registered businesses were certified. The questionnaires were filled electronically, since they were publicly accessible. During the research period, 117 questionnaires were returned, 20 were discarded due to incomplete data. The final sample file used in this study consisted of 97 enterprises.

\subsection{Level of representation of the sample file}

Using the statistical testing method, the level of representation of the sample file of companies was confirmed by the application of Pearson's chi-squared test $\left(\chi^{2}-\right.$ test), which is also known as the 'goodness-of-fit' test. It tests a null hypothesis, stating that the frequency distribution of certain events observed in a sample $\left(\mathrm{n}_{\mathrm{i}}\right)$ is consistent with a particular theoretical distribution $\left(\mathrm{np}_{\mathrm{i}}\right)$ at the level of statistical significance $(\alpha)$ for the appropriate degrees of freedom $(k-1)$, where $k$ is the number of fitted parameters. We used the following formula (Ostertagova, 2012):

$$
\chi^{2}=\sum_{i=1}^{m} \frac{\left(n_{i}-n p_{i}\right)^{2}}{n p_{i}}
$$

The calculation of the level of representation was done at the level of a statistical significance $\alpha=0.05$. The expected values of theoretical distribution were achieved from the certification bodies. The frequencies observed, and the expected, (theoretical) frequencies are shown in Table 1. The degree of freedom $(\mathrm{k}-1)$ is equal to three, since four categories of business organisation were defined.

Table $1-\chi^{2}-$ test due to enterprises' size

\begin{tabular}{lcccc}
\hline & $\mathrm{np}_{\mathrm{i}}[\%]$ & $\mathrm{n}_{\mathrm{i}}[\%]$ & $\left(\mathrm{n}_{\mathrm{i}}-\mathrm{np}_{\mathrm{i}}\right)^{2}$ & $\chi^{2}$ \\
\hline Micro enterprises & 10 & 7.12 & 8.29 & 0.83 \\
Small enterprises & 50 & 52,37 & 5.62 & 0.11 \\
Medium enterprises & 30 & 34.28 & 18.32 & 0.61 \\
Large enterprises & 10 & 6.23 & 14.21 & 1.42 \\
\hline$\Sigma$ & & & 2.97 \\
\hline
\end{tabular}

The $\chi^{2}$ value we achieved is lower than the critical $\chi^{2}$ value at the level of statistical significance $\alpha=0.05$ for 3 degrees of freedom (4 - 1), which in particular presents the value of 7.815 (value in statistical tables). 
Since $2.97<7.815$, we accept the null hypothesis and we state that the sample file of companies represents their theoretical distribution.

\subsection{Analysis and discussion of results}

In the introduction we set two research questions: (1) what are the attributes of the PI and (2) what is the minimum set of attributes of the PI that we could say about the consistent PMS? To answer to the first question we used an affinity diagram and compiled four groups of attributes, which are shown in Figure 1. Next, we looked for the set of minimum number of attributes of the PI, which form the basis of consistent PMS. We are not looking for a framework of PMS or specific indicators, and we are not telling about relations between different indicators. Our goal is to define the set of attributes, which should be defined for all performance indicators involved to a PMS.

Table 2 - Priority of the indicator attributes

\begin{tabular}{|c|c|c|c|c|c|}
\hline Indicator attribute & $\begin{array}{r}\text { Av. } \\
\text { Weight }\end{array}$ & $\begin{array}{c}\text { Min. } \\
\text { value }\end{array}$ & $\begin{array}{l}\text { Max. } \\
\text { value }\end{array}$ & $\begin{array}{r}\text { St. } \\
\text { deviation }\end{array}$ & Order \\
\hline T5: Target value (number) & 12.71 & 11 & 16.00 & 1.70 & 1 \\
\hline E5: Warning signal for the evaluator & 11.36 & 8 & 13.00 & 1.84 & 2 \\
\hline E3: Visualisation of the achieved performance & 10.29 & 6 & 13.00 & 2.43 & 3 \\
\hline E4: Action in case of a performance gap & 8.57 & 7 & 11.00 & 1.62 & 4 \\
\hline F3: Relation to the strategic goal & 7.71 & 5 & 10.00 & 1.70 & 5 \\
\hline F2: Relation to the business process & 6.71 & 5 & 9.00 & 1.38 & 6 \\
\hline F1: Name of the PI & 5.86 & 4 & 8.00 & 1.35 & 7 \\
\hline T2: Unit of the PI & 5.86 & 5 & 8.00 & 1.21 & 8 \\
\hline E1: Responsibility for the PI's evaluation & 5.07 & 3 & 6.00 & 1.17 & 9 \\
\hline I1: Responsibility for the data recording & 4.89 & 3 & 6.00 & 1.03 & 10 \\
\hline T4: Determinants of the target value definition & 3.89 & 2 & 5.10 & 1.37 & 11 \\
\hline F5: Responsibility for the PI's definition & 2.77 & 1 & 5.00 & 1.28 & 12 \\
\hline T1: Responsibility for the target value definition & 2.56 & 1.3 & 3.40 & 0.68 & 13 \\
\hline T3: Period defined for the target value achievement & 1.89 & 1 & 3.00 & 0.59 & 14 \\
\hline $\begin{array}{l}\text { F4: Strategic goal (name and identification number of the } \\
\text { strategic goal) }\end{array}$ & 1.74 & 1 & 2.40 & 0.41 & 15 \\
\hline I4: Source of data & 1.61 & 1 & 2.10 & 0.45 & 16 \\
\hline I5: Calculation formula & 1.52 & 0.9 & 2.00 & 0.45 & 17 \\
\hline I3: Place for data recording (name and destination of data store) & 1.47 & 0.8 & 2.10 & 0.49 & 18 \\
\hline I6: Automation of the calculation (manually/software) & 1.27 & 0.7 & 1.80 & 0.41 & 19 \\
\hline I2: Frequency of data recording & 1.15 & 0.55 & 1.80 & 0.45 & 20 \\
\hline E2: Frequency of the PI's evaluation & 1.11 & 0.6 & 1.80 & 0.41 & 21 \\
\hline
\end{tabular}


To determine the most suitable attributes for the company we performed an empirical study on a sampling of 97 companies. In the first stage, the companies had to determine the most important attributes of the PI for them. They had to assign a weight to each of 21 attributes and the sum of the weight is equal 100. The results are shown in Table 2 .

The research showed that the highest priority has specifying the target value, with the average value weight of 12.71 . The second highest importance is a warning signal for evaluator with a weight of 11.36. Others in order are: visualization of the achieved performance, action in case of a performance gap, and relation to the strategic goal and relation to the business process.

Table 3 -Occurrence of the indicator attributes in the sample companies

\begin{tabular}{lrrr}
\hline Indicator attribute & No. & $\%$ & Order \\
\hline F1: Name of the PI & 73 & 100.00 & 1 \\
T2: Unit of the PI & 73 & 100.00 & 2 \\
T5: Target value (number) & 73 & 100.00 & 3 \\
I4: Source of data & 73 & 100.00 & 4 \\
T3: Period defined for the target value achievement & 73 & 100.00 & 5 \\
I5: Calculation formula & 70 & 95.89 & 6 \\
I3: Place for data recording (name and destination of data store) & 68 & 93.15 & 7 \\
F4: Strategic goal (name and identification number of the strategic goal) & 56 & 76.71 & 8 \\
F3: Relation to the strategic goal & 46 & 63.01 & 9 \\
F2: Relation to the business process (name and identification number of the process) & 45 & 61.64 & 10 \\
I6: Automation of calculation (manually/software) & 40 & 54.79 & 11 \\
E3: Visualisation of the achieved performance & 39 & 53.42 & 12 \\
I1: Responsibility for data recording & 36 & 49.32 & 13 \\
T4: Determinants of the target value definition & 36 & 49.32 & 14 \\
E1: Responsibility for the PIs evaluation & 33 & 45.21 & 15 \\
T1: Responsibility for the target value definition & 31 & 42.47 & 16 \\
F5: Responsibility for the PI`s definition & 29 & 39.73 & 17 \\
I2: Frequency of data recording & 19 & 26.03 & 18 \\
E2: Frequency of the PIs evaluation & 12 & 16.44 & 19 \\
E5: Warning signal for the evaluator & 10 & 13.70 & 20 \\
E4: Action in case of the performance gap & 6 & 8.22 & 21 \\
\hline
\end{tabular}

In Table 3 are shown the results, where we asked the companies what attributes of the PI they have defined in their PMS. We did not ask about the consistency of the system if it meant the attributes the companies defined for all indicators. The 
first six attributes are: name of the PI, unit of the PI, target value (number), source of data, period defined for the target value achievement and calculation formula. This attributes are defined in most of the selected companies (from $95.89 \%$ to $100 \%$ companies).

A very interesting finding is that it created absolutely different rankings of attributes. We can see the difference in the case of importance (weight) and in the case of real occurrence. For example, warning signal for the evaluator is the second most important attribute but in fact it is determined for some or all indicators only by $13.70 \%$ companies. The similar result was also achieved in attribute E4 Action in case of the performance gap. This attribute is the fourth most important but in fact it is defined only by $8.22 \%$ companies. This difference represents a gap between what attributes companies would like to have defined in a PMS and what attributes they really have. According to this gap we can define the minimum set of attributes. This minimum set of attributes should be applied by companies on all performance indicators that are included in a PMS. To determine the minimum set of attributes we set the following conditions:

(1) weight of the attribute has to be at least 6 ,

(2) attribute has to be defined at least by 95 percent of the companies.

Based on these criteria we defined the group of twelve attributes of the PI that represent the core of consistent PMS of any company and in any economy sector, independently on enterprise's size. The minimum set of indicator attributes for the consistent performance management system is:

F1: Name of the PI

F2: Relation to the business process

F3: Relation to the strategic goal

T2: Unit of the PI

T3: Period defined for the target value achievement

T5: Target value (number)

I4: Source of data

I5: Calculation formula

E5: Warning signal for the evaluator

E3: Visualisation of the achieved performance

E4: Action in case of the performance gap 


\section{CONCLUSION}

In the introduction of our paper we set two research questions: (1) what are the attributes of the PI and (2) what is the minimum set of attributes of the PI that we could say about a consistent PMS? To answer to these questions we used two methodological approaches. The first of them was an affinity diagram, which was used to define attributes of the PI. We determined 21 attributes. The second one was an empirical study and we defined the minimum set of attributes that are necessary for a consistent PMS.

The main implications for companies are: (1) the knowledge of 21 attributes, by which it is able to describe all PI involved in a PMS, (2) specification of a minimum set of attributes that are important to determine to all PI, to make PMS consistent. Companies can select their own set of defined attributes of the PI; however the sense of consistency is that they use this set for all indicators. According to our research the best attributes were selected by companies as the most important and with the most frequent use. This is how we determined 12 attributes which represent "what companies want" and "what companies have". This gap represents an inconsistent PMS. 


\section{REFERENCES}

Abdullah, M., Hamid, M. R., Mustafa, Z., Husain, N., Idris, F., Suradi, N. R. M. and Ismail, W. R., 2012. Value-based total performance excellence model: A conceptual framework for organisations. Total Quality Management \& Business Excellence, 23(5-6), pp. 557-572.

Alfaro-Saiz, J.J., Carot-Sierra, J. M., Rodríguez-Rodríguez, R. and JabaloyesVivas, J M., 2011. Seeking organisational excellence by using the information coming from the EFQM excellence model as starting point: application to a real case. Total Quality Management \& Business Excellence, 22(8), pp. 853-868.

Berry, A. J., Coad, A. F., Harris, E. P., Otley, D.T. and Stringer, C., 2009. Emerging themes in management control: a review of recent literature. The British Accounting Review, 41(1), pp. 2-20.

Bisbe, J. and Otley, D., 2004. The effects of the interactive use of management control systems on product innovation. Accounting, Organizations and Society, 29(8), pp. 709-737.

Bonner, S. E., Hastie, R., Sprinkle, G. B. and Young, S. M., 2000. A review of the effects of financial incentives on performance in laboratory tasks: implications for management accounting. Journal of Management Accounting Research, 12, pp. 19-64.

Chenhall, R.H., 2003. Management control systems design within its organizational context: findings from contingency-based research and directions for the future. Accounting, Organizations and Society, 28(2-3), pp. 127-168.

Chenhall, R.H., 2005. Integrative strategic performance measurement systems, strategic alignment of manufacturing, learning and strategic outcomes: an exploratory study. Accounting, Organizations and Society, 30(5), pp. 395-422.

Chenhall, R.H. and Euske, K.J., 2007. The role of management control systems in planned organizational change: an analysis of two organizations. Accounting, Organizations and Society, 32(7-8), pp. 601-637.

Doeleman, H.J., Have, S. and Ahaus, K., 2012. The moderating role of leadership in the relationship between management control and business excellence. Total Quality Management \& Business Excellence, 23(5-6), pp. 591611.

Evans, J.R., Ford, M. W., Masterson, S. S. and Hertz, H. S., 2012. Beyond performance excellence: research insights from Baldrige recipient feedback. Total Quality Management \& Business Excellence, 23(5-6), pp. 489-506.

Flapper, P. S., Fortuin, L. and Stoop, P., 1996. Towards consistent performance management systems. International Journal of Operations \& Production Management, 16(7), pp. 27-37. 
Ferreira, A. and Otley, D., 2009. The design and use of performance management systems: An extended framework for analysis. Management Accounting Research, 20 (4), pp. 263-282.

Gavurová, B., Šoltés, M. and Balloni, A. J., 2014. Ekonomický význam využívania informačno-komunikačných technológií $\mathrm{v}$ systéme zdravotníctva. Ekonomicky casopis, 62(1), pp. 83-104.

Heras-Saizarbitoria, I., Marimón, F. and Casadesús, M., 2012. An empirical study of the relationships within the categories of the EFQM model. Total Quality Management \& Business Excellence, 23(5-6), pp. 523-540.

Ostertagová, E., 2012. Aplikácia štatistických testov dobrej zhody. Transfer inovácií, 14(23), pp. 72 - 74.

Otley, D., 1994. Management control in contemporary organizations: towards a wider framework. Management Accounting Research, 5(3-4), pp.289-299.

Otley, D., 2008. Did Kaplan and Johnson get it right? Accounting, Auditing \& Accountability Journal, 21(2), pp. 229-239.

Kaplan, R.S. and Norton, D.P., 1996. The Balanced Scorecard: Translating Strategy into Action. Boston: Harvard Business School Press.

Kaplan, R.S. and Norton, D.P., 2000. Strategy-focused Organization: How Balanced Scorecard Companies Thrive in the New Business Environment. Boston: Harvard Business School Press.

Kaplan, R.S. and Norton, D.P., 2004. How strategy maps frame an organization's objectives. Financial Executive, 20(2), pp. 40-45.

Wang, W. T., 2012. Evaluating organisational performance during crises: A multi-dimensional framework. Total Quality Management \& Business Excellence, 23(5-6), pp. 673-688.

Závadský, J. and Závadská, Z., 2014. Utilisation of business process models in managerial practice: An empirical study in Slovak companies certified to the ISO 9001 standard. Total Quality Management \& Business Excellence, 24(3-4), pp. 319-337. 


\section{ABOUT THE AUTHORS}

Ján Závadský, Dr. Asc. Prof., Faculty of Economics, Matej Bel University, Tajovskeho 10, 97590 Banska Bystrica, Slovak Republic, e-mail: jan.zavadsky@umb.sk.

Vladimír Hiadlovský, Dr., Faculty of Economics, Matej Bel University, Tajovskeho 10, 97590 Banska Bystrica, Slovak Republic, e-mail: vladimir.hiadlovsky@umb.sk. 